\title{
A Study of Risk Factors for Breast Cancer in a Primary Oncology Clinic in Benghazi-Libya
}

\author{
Fatma Ben Khaial ${ }^{1}$, Zuhir Bodalal ${ }^{2, *}$, Amal Elramli $^{1}$, Fayek Elkhwsky ${ }^{1}$, Adel Eltaguri ${ }^{3}$ and \\ Riyad Bendardaf ${ }^{4}$
}

${ }^{1}$ Family and Community Medicine, Faculty of Medicine, Benghazi University, Benghazi, Libya

${ }^{2}$ Faculty of Medicine, Libyan International Medical University, Benghazi, Libya

${ }^{3}$ Department of Pediatrics, Benghazi Medical Center, Benghazi, Libya

${ }^{4}$ Department of Medicine, Oncology Unit, University Hospital Sharjah, Sharjah, UAE

\begin{abstract}
Introduction: Libya is a North African country classified under the Eastern Mediterranean Regional Office. In response to the general paucity of literature regarding cancer in Libya, this study aims to analyze various risk factors for breast cancer among patients in Benghazi, Libya.

Material and Methods: Using records from a major primary oncology clinic, data was gathered from breast cancer patients. A total of 301 patients were diagnosed with breast cancer in the study period. For the purpose of risk factor determination, this hospital-based case control study consisted of 212 recently diagnosed cases of breast cancer attending the oncology clinic at Al-Jamhouria hospital in Benghazi. Age matched controls $(n=219)$ were randomly enrolled from other medical departments of Al-Jamhouria hospital and the general population visiting the hospital. Chi square was used to assess significance of the risk factors and the corresponding odds ratio (O.R.) and $95 \% \mathrm{Cl}$ were calculated to assess the magnitude of associations.
\end{abstract}

Results: A total of 1478 cases presented to the gynecological oncology clinic at Al-Jamhouria hospital during the period of 2007-2008. Of these cases, around $20 \%(n=301)$ were breast cancer patients. The average age of presentation was 49 years \pm S.D 13 years, with most of the cases $(61 \%, n=184)$ being premenopausal. Over $90 \%(n=273)$ of breast cancer patients are diagnosed at stage II or later. More than $16 \%$ of cases seek medical attention when the malignancy has already reached stage IV. Diabetes, hypertension and family history of other malignancies were found to significantly increase the risk of developing breast cancer.

Discussions: A range of socioeconomic risk factors were also analyzed (i.e. parity, breastfeeding etc...) and some were found to be protective. Libyan breast cancer cases are slightly older compared to the rest of the Arab world, but are younger than their counterparts in the West. The major issue in the Libyan scenario is delayed presentation which significantly worsens the prognosis. Hence, all the recommendations focus on increased awareness, the implementation of a national cancer control plan and a national screening program and training healthcare professions in palliative care.

Keywords: Breast cancer, Libya, Arab World, Epidemiological studies, Early Detection of Cancer.

\section{INTRODUCTION}

Libya is a coastal North African nation classified under the Eastern Mediterranean Regional Office (EMRO). It has two principal cities; Tripoli (the capital) and Benghazi (the main city of eastern Libya). According to 2006 Libyan census, 674,951 people live in the eastern city of Benghazi $-30.2 \% \quad(n=204,206)$ being women aged 15 to 54 years.

Cancer is the fourth leading cause of death in the Eastern Mediterranean Region (EMR) and the incidence is increasing rapidly. Previously, breast malignancies were thought to be the second most common form of cancer [1, 2]. However, it was recently found that, in Libya, breast cancer was the most common malignancy overall as well as being the most

*Address correspondence to this author at the Department of Medicine, Faculty of Medicine, Libyan International Medical University, P.O. Box 15016, Benghazi, Libya; Tel: +218-91-478-9141; Fax: +218-61-2233909;

E-mail: zuhir.bodalal@limu.edu.ly common carcinoma in females [3]. Breast cancer is already the leading female cancer in terms of global cancer incidence [4]. It is by far the most common gynecological malignancy either in Libya or in other Arab nations $[1-3,5,6]$.

While most literature has focused on incidence calculation, no study has been performed to determine the level of association between certain risk factors and the possibility of developing breast cancer in Libya. This study aims to analyze various risk factors for breast cancer among patients in Benghazi and compare them with reported figures.

\section{METHODOLOGY}

\section{(i) Ethical Approval}

This study was approved by the Libyan International Medical University Ethical Committee. 


\section{(ii) Data}

Data was gathered prospectively from patient records at the gynecological oncology clinic at AlJamhouria hospital. Information regarding date of diagnosis, age, occupation, marital status, parity, history of breast feeding, symptom, family history, oral contraceptive use, history of prior breast biopsy, stage and histological type of breast cancer at the time of study and treatment were collected. Incidence rates were note calculated during the study since the site of data collection served as one of multiple possible centers to receive cancer treatment (at the time).

\section{(iii) Statistical Methods}

A total of 301 patients were diagnosed with breast cancer in the study period. For the purpose of risk factor determination, this hospital-based case control study consisted of 212 recently diagnosed cases of breast cancer attending the oncology clinic at AlJamhouria hospital in Benghazi. Age matched controls $(n=219)$ were randomly enrolled from other medical departments of Al-Jamhouria hospital and the general population visiting the hospital. Chi square was used to assess significance of the risk factors and the corresponding odds ratio (O.R.) and $95 \% \mathrm{Cl}$ were calculated to assess the magnitude of associations.

\section{RESULTS}

A total of 1478 cases presented to the gynecological oncology clinic at Al-Jamhouria hospital during the period of 2007-2008. One-fifth of the patients $(20 \%, n=301)$ suffered from breast cancer. The mean age was 49 years ( \pm 13 years) with peak occurrence being observed in the $45-54$ year age group (range 28 - 98 years). Nearly two-thirds $(61 \%$, $\mathrm{n}=184$ ) of the breast cancer cases were premenopausal.

Breast lump $(63 \%, n=189)$ and mastalgia (14\%, $\mathrm{n}=42$ ) were the two most common presenting complaints. The various presentations of breast cancer patients are shown in Figure 1. Two thirds $(66 \%$, $\mathrm{n}=199$ ) of the breast carcinoma patients presented at late stages of the disease (i.e. stage III or IV). This is further depicted in Figure 2.

Histopathologically, the most common form of breast cancer was invasive ductal carcinoma $(74.2 \%$, $\mathrm{n}=223$ ), with infiltrative ductal and infiltrative lobular carcinoma coming up in second and third place forming $23.5 \%(n=71)$ and $2.3 \%(n=7)$ respectively.

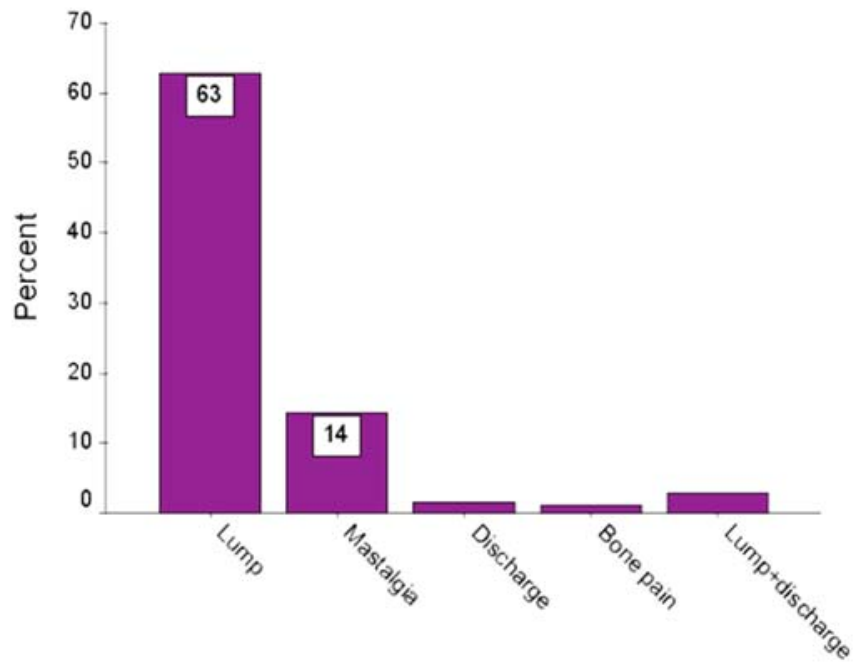

Figure 1: A display of the various presenting complaints among Libyan of breast cancer patients.

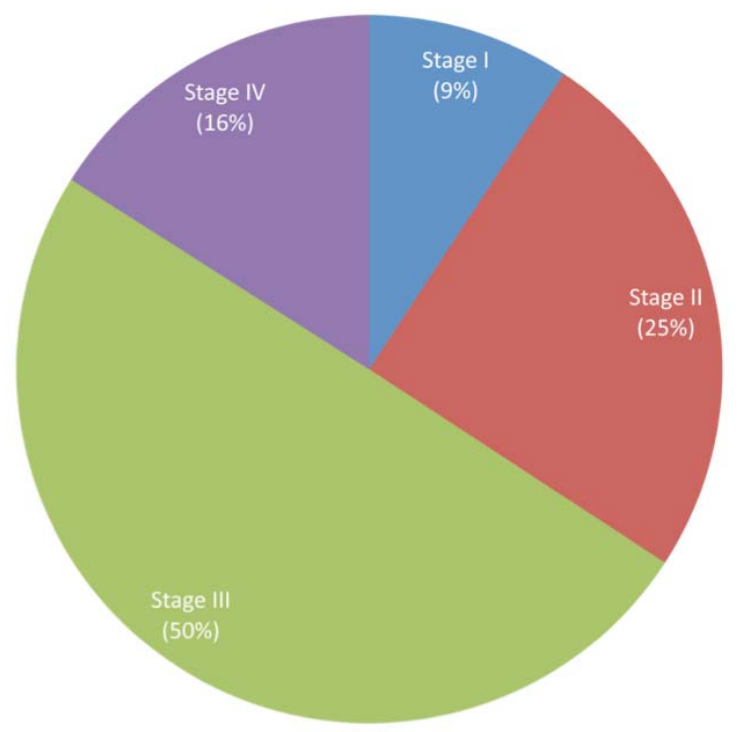

Figure 2: The distribution of Libyan breast cancer patients according to stage at diagnosis.

Parity $(\mathrm{OR}=3.7,95 \% \mathrm{Cl}=1.8-7.3)$, breastfeeding $(\mathrm{OR}=3.7,95 \% \mathrm{Cl}=1.8-7.3)$, and the presence of an active job $(\mathrm{OR}=3.7,95 \% \mathrm{Cl}=1.8-7.3)$ were found to be protective socioeconomic parameters for breast malignancies (Table 1).

Table 1: The Impact of Various Socioeconomic Factors on the Development of Breast Cancer

\begin{tabular}{|c|c|c|}
\hline Risk factor & OR & (95\%Cl) \\
\hline \hline Marital status & 3.8 & $(1.50-9.80)$ \\
\hline Parity & 0.5 & $(0.40-0.80)$ \\
\hline Breast feeding & 0.08 & $(0.04-0.10)$ \\
\hline Occupation & 0.36 & $(0.20-0.50)$ \\
\hline
\end{tabular}


Family history of breast cancer $(\mathrm{OR}=3.7,95 \% \mathrm{Cl}=$ 1.8-7.3), diabetes $(\mathrm{OR}=2.3, \quad 95 \% \mathrm{Cl}=1.5-3.5)$, hypertension $(\mathrm{OR}=1.4, \quad 95 \% \mathrm{Cl}=1.1-2.0)$, and concomitant DM/HTN $(\mathrm{OR}=3.7,95 \% \mathrm{Cl}=2.5-5.5)$ were found be significant risk factors for developing breast cancer (Table 2).

Table 2: The Significance of Certain Medical Risk Factors on the Development of Breast Cancer (DM= Diabetes Mellitus; HTN = Hypertension, $\mathrm{H} / \mathrm{O}=$ History of)

\begin{tabular}{|c|c|c|}
\hline Risk factor & OR & $\mathbf{( 9 5 \% \mathbf { C l } )}$ \\
\hline \hline Both DM and HTN & 3.7 & $(2.5-5.5)$ \\
\hline DM alone & 2.3 & $(1.5-3.5)$ \\
\hline HTN alone & 1.4 & $(1.1-2.0)$ \\
\hline Family history of any other cancer & 3.7 & $(1.8-7.3)$ \\
\hline
\end{tabular}

\section{DISCUSSION}

Overall, there has been an overall paucity of comprehensive cancer epidemiology research in the Arab nations. The rate of breast cancer cases in female oncology clinics in neighbouring countries is similar to Libya; whereas other countries have a significantly higher incidence. This is fundamentally different from age-standardized rates, where population is used as a denominator (after adjusting for age distribution). However, for the sake of preliminary comparison, these figures will suffice.

In Morocco, the most frequently occurring cancer in females was cervical uterine neoplasia $(35 \%)$ followed by breast cancer (22.3\%), which was often diagnosed at advanced stages [7]. Between 2004 and 2010, breast carcinoma represented $22 \%$ of the total number of registered Yemeni women with cancer [8].

Breast cancer constituted $38.2 \%$ of all cancer cases among Lebanese females in 2004. Likewise, the figures previously reported for Jordan, Cyprus and Saudi Arabia were $36.2 \%, 35.4 \%$ and $22.4 \%$ respectively [9]. In Egypt, approximately $35 \%$ of all female cancer was breast cancer [10]. The percentage of Libyan breast cancer patients registered at oncology clinics were found to be low when compared with the European and North American figures $(27.3 \%$ and $31.3 \%$ of cancers in females, respectively) [11].

Even within the different regions of the same country, variation has been reported. One third (33.7\%, $\mathrm{n}=101$ ) of the female cancer patients admitted to $\mathrm{AOI}$
(African Oncology Institute in Western Libya) were breast cancer cases [12]. The aforementioned institute even expressed concerns that the incidence of breast cancer in the west of Libya was on the rise [12].

The average age of diagnosis in the Benghazi clinic was relatively high when compared to other Arab countries. In Yemen, the median age obtained was 45 years with a mean age of 46 years $(S D=12)$. Similarly, the highest incidence of cases was recorded in the 4150 year old age group (35\%) with an interestingly high incidence being observed in the 21-40 year group [8]. In Lebanon, the median age at diagnosis was 52.5 years with the highest rates being displayed in the 50 59 year age group [9]. The AOI (in Western Libya) reported different numbers. The average age of a breast cancer patient in Western Libya was $46.1 \pm 12.3$ years [12].

A meta-analysis examined all available studies dealing with the age of Arab breast cancer patients [13]. They reported that the average age at diagnosis was 48 years $(S D=2.8$, range $=43-52$, median $=48.5$, mode $=45$ years) [13]. The authors of the study proposed that the average and median age of presentation of Arab women is a decade earlier than their Western counterparts [13, 14]. This is congruent with the notion that most breast cancer cases in the developing world are premenopausal whereas those in the developed nations are postmenopausal [12]. Despite similar staging and grade, women who were diagnosed in Libya under the age of $35 \%$ had a worse prognosis [8].

The distribution of patients according to stage corroborated well with values obtained in previous studies done on breast cancer cases in Tripoli in 2005 [15] and another done in 2006 using patients from the Sibratha (AOI) registry [12].

Such a high incidence of patients at advanced stages is more likely an indicator of late presentation as opposed to intrinsic aggressiveness of the malignancy. Among the most prominent reasons for delayed seeking of medical assistance were cultural and social constraints [2]. Similar to Benghazi, the majority of the cancer patients in Western Libya (76\%) were diagnosed with invasive ductal carcinoma [12].

There was a statistically significant difference between the cases and the control group in breast feeding, parity, marital status and occupation as protective factors (Table 1). These finding are similar to 
results in Egypt demonstrating that nulliparity, early age of menarche, late age at first delivery, late age at menopause, history of spontaneous miscarriages, heavier weight as well as fibrocystic breast disease are important risk factors for breast cancer [16].

A Slovenian study assessed the relationship between parity and breast cancer risk and found that parity was associated with a $5.3 \%$ annual increase in the odds of breast cancer, among parous women. They also reported that post-menopausal women have a reduced breast cancer risk compared with premenopausal women of the same age [17]. A study conducted in Texas found that $34 \%$ of breast cancer cases reported a family history of breast carcinoma and only $5 \%$ reported a family history of ovarian carcinoma [18]. The findings also agree with the international consensus on cancer linked diabetes and hyperinsulinemia and their association with increased cancer risk and poor prognosis [19].

\section{CONCLUSIONS AND RECOMMENDATIONS}

A number of recommendations can be made:

(i) Breast cancer is a serious condition that affects the whole world. This is particularly true in Libya where most of the cases present to the hospital at advanced stages. Screening programs in Libya for breast cancer are virtually non-existent.

Traditionally, medical research has focused more on management than prevention (i.e. breast self-examination (BSE) and clinical breast examination (CBE)) [20]. However, this seems to hit the core of our dilemma with breast carcinomas. The public needs to be educated in BSE and CBE in order to help avoid the catastrophic situation of late presentation [21].

(ii) In order to overcome the constraints of detection, a screening program needs to be setup with massive outreach into society. Women in our society may need to be targeted at an earlier age compared to their counterparts in the Western societies; the same can be said for most of the Arab countries [13]. Additionally, the risk factors studied need to be taken into consideration

(iii) Ideally these programs need to be integrated into the primary healthcare centers. Naturally, such an endeavor should be preceded by a national cancer control plan (which is also missing) [22]. (iv) Many breast cancer patients initially avoid going to the hospital for proper diagnosis or management because of their fatalistic attitude towards cancer and the dread of a stigma [3]. Healthcare professionals should collaborate with members of the media in order to change this perception and increase awareness of the issue.

(v) With the large number of cases being diagnosed at later stages, we need to have core staff trained in palliative treatment. Moreover, proper facilities for end-of-life care need to be erected to appropriately deal with these patients.

\section{CONFLICTS OF INTEREST}

The authors declare no conflicts of interest.

\section{REFERENCES}

[1] El Mistiri M, Verdecchia A, Rashid I, El Sahli N, El Mangush M, Federico M. Cancer incidence in eastern Libya: The first report from the Benghazi Cancer Registry, 2003. Int J Cancer 2006; 120: 392-7.

http://dx.doi.org/10.1002/ijc.22273

[2] El Mistiri M, Pirani M, El Sahli N, El Mangoush M, Attia A, Shembesh $\mathrm{R}$, et al. Cancer profile in Eastern Libya: incidence and mortality in the year 2004. Annals of oncology 2010; 21(9): 1924-6.

http://dx.doi.org/10.1093/annonc/mdq334

[3] Bodalal Z, Azzuz R, Bendardaf R. Cancers in Eastern Libya: First results from Benghazi Medical Center. World journal of gastroenterology: WJG 2014; 20(20): 6293. http://dx.doi.org/10.3748/wjg.v20.i20.6293

[4] Ferlay J, Shin H, Bray F, Forman D, Mathers C, Parkin D. GLOBOCAN 2008, cancer incidence and mortality worldwide: IARC CancerBase No. 10. Lyon, France: International Agency for Research on Cancer 2010; 2010: 29.

[5] El Saghir NS, Khalil MK, Eid T, El Kinge AR, Charafeddine $\mathrm{M}$, Geara $\mathrm{F}$, et al. Trends in epidemiology and management of breast cancer in developing Arab countries: a literature and registry analysis. International Journal of Surgery 2007 5(4): 225-33. http://dx.doi.org/10.1016/j.jisu.2006.06.015

[6] Ben Khaial F, Bodalal Z, Elramli A, Elkhwsky F, Eltaguri A, Bendardaf R. Cervical cancer in North-eastern Libya: 20002008. Journal of Obstetrics \& Gynaecology 2014; (0): 1-4.

[7] Chaouki N, El Gueddari B. [Epidemiological descriptive approach of cancer in Morocco through the activity of the National Institute of Oncology 1986-7]. Bulletin du cancer 1990; 78(7): 603-9.

[8] El-Zaemey S, Nagi N, Fritschi L, Heyworth J. Breast cancer among Yemeni women using the National Oncology Centre Registry 2004- 2010. Cancer epidemiology 2012; 36(3): 24953.

http://dx.doi.org/10.1016/j.canep.2012.01.006

[9] Lakkis NA, Adib SM, Osman MH, Musharafieh UM, Hamadeh GN. Breast cancer in Lebanon: incidence and comparison to regional and Western countries. Cancer epidemiology 2010; 34(3): 221-5. http://dx.doi.org/10.1016/j.canep.2010.02.013

[10] Mokhtar N, Gouda I, Adel I. Cancer pathology registry 20032004 and time trend analysis. Department of pathology, $\mathrm{NCl}$ 2007. 
[11] Parkin DM, Fernández LM. Use of statistics to assess the global burden of breast cancer. The breast journal 2006; 12(s1): S70-S80. http://dx.doi.org/10.1111/j.1075-122X.2006.00205.x

[12] Boder JME, Abdalla FBE, Elfageih MA, Abusaa A, Buhmeida A, Collan Y. Breast cancer patients in Libya: Comparison with European and central African patients. Oncology letters $2011 ; 2(2): 323$.

[13] Najjar H, Easson A. Age at diagnosis of breast cancer in Arab nations. International Journal of Surgery 2010; 8(6): 448-52.

http://dx.doi.org/10.1016/j.ijsu.2010.05.012

[14] WHO. World health statistics 2008. Geneva: WHO; 2008 2009.

[15] Elhabbash M, Alwindi A. Survival of breast cancer in women under 35 years. European Journal of Cancer Supplements 2008; 6(7): 76-7.

http://dx.doi.org/10.1016/S1359-6349(08)70410-5

[16] Ibrahim A, Massoud A, Buttler P, Fahim H. Breast cancer risk, a case-control study among Egyptian women. Int $\mathrm{J}$ of Cancer 1987; 16: 347-55.

[17] Robertson C, Primic-Zakelj M, Boyle P, Hsieh CC. Effect of parity and age at delivery on breast cancer risk in Slovenian women aged 25- 54 years. International journal of cancer 1997; 73(1): 1-9.

http://dx.doi.org/10.1002/(SICl)10970215(19970926)73:1<1::AID-IJC1>3.0.CO:2-U
[18] Gonzalez-Angulo AM, Broglio K, Kau SW, Eralp Y, Erlichman $\mathrm{J}$, Valero $\mathrm{V}$, et al. Women age $\leq 35$ years with primary breast carcinoma. Cancer 2005; 103(12): 2466-72. http://dx.doi.org/10.1002/cncr.21070

[19] Hu FB, Manson JE, Stampfer MJ, Colditz G, Liu S, Solomon $\mathrm{CG}$, et al. Diet, lifestyle, and the risk of type 2 diabetes mellitus in women. New England Journal of Medicine 2001; 345(11): 790-7.

http://dx.doi.org/10.1056/NEJMoa010492

[20] Lodge $M$, Corbex $M$. Establishing an evidence-base for breast cancer control in developing countries. The Breast 2011; 20: S65-S9.

http://dx.doi.org/10.1016/j.breast.2011.01.012

[21] Gligorov J, Arsovski O, Belkacemi Y, Bachouchi M, PenaultLlorca $\mathrm{F}$, Chauvet M-P, et al. Guidelines, minimal requirements and standard of cancer care around the Mediterranean Area: Report from the Collaborative AROME (Association of Radiotherapy and Oncology of the Mediterranean Area) working parties AROME. Critical Reviews in Oncology Hematology 2011; 78(1): 1-16. http://dx.doi.org/10.1016/i.critrevonc.2010.03.007

[22] Omar S, Alieldin N, Khatib O. Cancer magnitude, challenges and control in the Eastern Mediterranean region. Eastern Mediterranean health journal= La revue de sante de la Mediterranee orientale $=$ al-Majallah al-sihhiyah li-sharq almutawassit 2006; 13(6): 1486-96. 